\title{
Using Telemedicine in Practice: Implications for Workforce Development
}

\author{
Alison Marshall* \\ University of Cumbria, United Kingdom \\ Elaine Bidmead \\ University of Cumbria, United Kingdom
}

\begin{abstract}
The aim of this article is to present a discussion of the impact of telemedicine on professional practice, and the implications for the workforce. Telemedicine, or the use of video-conferencing for remote consultations between clinician(s) and patients, is now a mature technology. Many pilot studies have taken place, generally showing positive benefits to patients. There is emerging evidence that the impact on staff is more mixed; with concerns about changes to job role, skills development, and poor understanding of the organisational benefits. Evidence also highlights enablers of successful telemedicine implementation, including senior leadership, peer motivation, understanding of patient benefits, and time for safe experimentation. Following a review of qualitative data from four case study telemedicine projects undertaken within the authors' research group, evidence from published literature is discussed. The four projects explore telemedicine services provided between an acute hospital service and nursing homes (remote assessment of swallowing difficulties), an acute hospital service and home (video-link to renal patients undergoing home dialysis), between a specialist teaching hospital service and a district general hospital (fetal abnormalities ultrasound telemedicine clinic), and a survey of mental health professionals across acute and community services within a locality. The introduction of telemedicine at scale requires an organisational and system-level approach that recognises the specific challenges and issues for the workforce. Education and training need to be provided at all levels. In conclusion: there are significant opportunities to realise the benefits of remote consultations, to improve the patient experience and staff productivity, if workforce issues are addressed.
\end{abstract}

Keywords: digital health; skills; telemedicine; workforce

${ }^{*}$ Corresponding Author: Alison Marshall, Professor of Health Technology and Innovation,

Department of Health, Psychology and Social Studies, University of Cumbria, Bowerham Road,

Lancaster, LA1 3JD United Kingdom

Email: alison.marshall@cumbria.ac.uk

Journal URL: http://e-learning.coventry.ac.uk/ojs/index.php/pblh

Marshall, A. and Bidmead, E. (2018) 'Using telemedicine in practice: Implications for workforce development'. International Journal of Practice-based Learning in Health and Social Care, 6 (2), 111-124

(c) 2018 Alison Marshall and Elaine Bidmead. This Open Access article is distributed under the terms of the Creative Commons Attribution Attribution-Non-Commercial No Derivatives 4.0 International License (https://creativecommons.org/licenses/by-nc-nd/4.0/ ), which permits unrestricted non-commercial use, distribution, and reproduction in any medium, provided the original work is properly cited and is unaltered. 


\section{Introduction}

The work described here considers the practice of telemedicine consultations to deliver clinical services, and its implications for workforce development. Terminology in this field is inconsistent, and there are no agreed global definitions, so we present at the outset our own definitions.

A telemedicine consultation is one in which a clinician (such as a doctor, nurse, allied health professional) and patient are in two different places, communicating using video-conferencing. The purpose is to avoid the need to travel by either the patient or the clinician. A diagnostic procedure may be involved, or the consultation may be used for disease management or coaching and is purely conversational. In some cases, a second individual is with the patient, as an assistant. This may be another skilled clinical professional, a healthcare assistant or even a carer, whose role may be to operate some equipment, or to carry out instructions by the remote clinician where a physical examination is required. It is even possible that a second specialist may be involved at a third location. Telemedicine may also refer to video-conferencing where the patient is not present - case conferences, multi-disciplinary team meetings or second opinion discussions. These latter cases, however, are not discussed in this article, which is restricted to video-conferencing telemedicine consultations between a clinician and a patient, with or without an assistant. It should be noted that this terminology is not consistently used, so some of the articles discussed use different terms to denote video-linked. There are no universally accepted definitions, and some authors use the term 'telehealth' or 'e-health' for the same activity. More generic terms also used are 'technology enabled health care', 'connected care', or 'remote consultations'.

The technology (i.e. video-conferencing equipment and network connections) to support such clinical services is mature and widely used in other sectors, including domestic and leisure uses. Whilst low cost or free options are available for home users (for example, Skype ${ }^{\circledR}$ or FaceTime $\left.{ }^{\circledR}\right)$, professional grade technologies are now widely available that overcome issues of security and reliability, and address connectivity issues in areas where this is limited. Pilot studies have tended to focus on the patient experience, clinical validity and health economics. Studies looking at the impact on the workforce, their attitudes and perceptions, have been more limited. There is, however, some evidence that these workforce issues constitute some of the barriers to greater adoption of telemedicine. In this article, we review evidence - from our own work and that published by others - related to telemedicine and workforce development, and propose and discuss key themes, concluding with recommendations for how they may be addressed.

A systematic review of reviews of the effectiveness of telemedicine (Ekeland, Bowes, and Flottorp 2010: 736-771) identified 80 reviews, and cited three studies specifically about video consultations. The authors comment on the need for service-specific development, or 'localisation'. However, they give no explicit discussion of the impact on the workforce. One of the cited reviews (Verhoeven et al. 2007: e37) commented that staff training and implementation activities were important. Smith and Maeder (2010) explore the views of nurses towards use of digital technologies in practice. The article notes the lack of education to provide nurses with appropriate knowledge and skills. The authors reflect that this needs to be accompanied by organisational changes in the workplace and changes in policy. Policy changes (for example, in England, the Five Year Forward View [NHS England 2014], and the Scottish e-Health Strategy [NHS Scotland 2015]) have started to emerge since 2010, but without a planned approach to organisational changes. Volpe, Boydell, and Pignatiello (2013: 4) address the issues of workforce attitudes via a web survey of child psychiatrists in Canada. Respondents were influenced by concerns about adequate technical and infrastructure support, as well as remuneration models. Participants who had received training in telemedicine as part of their undergraduate medical studies were more comfortable with using it in the field.

There is clearly an emerging understanding that using video in consultations changes the nature of the interaction with the patient. LeRouge, Garfield, and Collins (2012: 622-636) propose that the use of video requires a new description of the service relationship which they term an 
'advanced encounter'. Both patients and staff need appropriate preparation and training, which the provider organisation needs to recognise and support. Saliba et al. (2012: 793-809) looked specifically at cross-border telemedicine. They considered examples where health services were provided via a video link to countries or regions with limited health professional resources, to fulfil a (locally) unmet need. Although the cross-border model has some specific issues associated with it, there are some generic findings of wider relevance. These included challenges around clinical liability and governance (uncertain liability if a remote specialist provides advice to a patient also under the care of a local professional); sustainability issues where initiatives are run as externally funded pilots; and issues associated with organisational culture where change does not have executive leadership. Zanaboni and Wootton (2012: 1) assert that provision of technology is not enough: "unless health professionals are persuaded, the equipment will not be used".

One of the most compelling clinical cases for using telemedicine is in stroke diagnosis, where the use of video assessment can save lives by enabling life-saving thrombolysis treatment to be given if stroke is diagnosed within the critical time window. French et al. (2013: 125) reviewed 20 telestroke projects and identified the main challenges all to be associated with professional usability, including clinical perceptions of benefits to them and the organisation, workability, and measures of success. In spite of the compelling case, many of the pilots have not proceeded to adoption. Sørensen et al. (2014: 1) are clear that "technology is not the issue" and cite staff motivation as a barrier to implementation of telestroke in Norway.

\section{Methods}

This is a discussion paper, emerging from a body of work in the field where common themes have been identified. Previous work by the authors has focused on specific qualitative studies of attitudes and perceptions of telemedicine interventions. These have been separately published and describe the findings for each of the relevant clinical communities (Bidmead et al. 2015: 155-168, Bidmead and Marshall forthcoming, Ditchburn and Marshall 2017: 175-182, University of Cumbria for the Cumbria Rural Health Forum 2016: online). The authors noted a number of generic themes, which have been further discussed through discussions with health professionals, managers and commissioners, as well as with colleagues, collaborators and our students. This discussion, and the emergence of our opinions, have been developed alongside other activities rather than a separately constituted research programme.

This article presents a review of our own published data. In each of the studies, a number of stakeholders were asked to reflect on the use of video to deliver a particular patient-facing service, through surveys, semi-structured interviews, and focus groups. Each of these is described more fully below and in the published references.

The authors identified themes that recur across the four case studies and propose professional and organisational development actions to address these themes. The themes and proposals are enriched further by a review of related published work. Literature review in this field is hampered by inconsistency of terminology. Our own definitions are presented at the outset of this paper, but other workers use 'telehealth', 'e-health' or simply prepend 'tele' to their own discipline ('teleswallowing', 'teleradiology' etc.). Hence, whilst comprehensive, the literature review is not claimed to be exhaustive.

The following paragraphs describe the four case studies undertaken by the authors.

\section{Remote assessment of swallowing difficulties (teleswallowing)}

Patients in nursing homes with swallowing difficulties (dysphagia) were assessed remotely by speech and language therapists (SLTs), using video. A nurse assisted the SLT and acted under direction to examine the patient, and provide them with appropriate drinks or food. The SLT was able to see and talk to the patient directly, and to hear and observe their responses. This meant 
that patients could receive timely assessment, travel time for SLTs was eliminated, and nursing home staff gained more insight into care and management of dysphagia (Bidmead et al. 2015: 155-168).

\section{Video-link to renal patients undergoing home dialysis (renal telemedicine)}

A video-link was provided to home haemodialysis patients, so that a specialist renal nurse was able to provide remote support, and solve any problems that had arisen. This meant that the period of training that patients needed to undergo before being able to 'go solo' with their dialysis could be reduced, community based nurses did not need to attend to confident patients so frequently, and more patients could be offered home dialysis (Ditchburn and Marshall 2017: 175182).

\section{Fetal abnormalities ultrasound clinic, attended by a remote fetal medicine consultant and local sonographer (fetal telemedicine)}

Pregnant women who would normally be referred on receiving an abnormal or anomalous ultrasound scan, were able to be scanned again with the fetal medicine consultant linking remotely by video. The consultant was able to view the live scan in real time and to direct the sonographer performing the scan and then to diagnose and advise the patient directly. This meant that women were saved from undertaking travel (typically a two- to three-hour journey each way), sonographers and midwives present at the consultation could learn more about the management of the case and provide more direct support (Bidmead and Marshall forthcoming).

\section{Survey of mental health professionals}

Mental health consultants, nurses, and social care providers were surveyed online to ascertain their views on use of video for psychiatric assessments, therapy, and emergency support to mental health patients. They were asked to comment on when and for which types of patients (if any) they thought video could be useful (University of Cumbria for the Cumbria Rural Health Forum 2016: online).

The four case studies used a common methodology, which we introduce below, to elicit attitudes and perceptions to a new innovative technology by health professionals.

There is a tendency that telemedicine services can be successfully piloted, but fail to be adopted at scale due to organisational or workforce barriers. Peddle (2007: 595-614) discusses the difficulties in effectively evaluating telehealth programmes in a state of "a perpetual pilot study". There is an emerging appreciation that such innovations are complex and a formative, collaborative approach is beneficial (Ekeland, Bowes, and Flottorp 2010, 736-771). Normalisation process theory (NPT) was developed to enable stakeholders to engage with a complex innovation, collaborate to make it workable, and integrate it into practice (May and Finch 2009: 535-554, May et al. 2009: 29). The approach identifies four different stakeholder groups - patients/carers/service users, health professionals/clinical staff users, management, technologists. A structured set of issues is explored with each group to elicit challenges and benefits, particularly considering 'workability' and organisational fit. NPT requires significant resource and organisational commitment. The Stakeholder Empowered Adoption Model (StEAM) was developed as a modified approach where smaller scale studies are desirable (Bidmead et al. 2015: 155-168, Bidmead and Marshall forthcoming, Ditchburn and Marshall 2017: 175-182, Marshall 2013: 63-68); it uses elements of NPT and the Technology Acceptance Model (TAM) (Davis 1989: 319, Venkatesh et al. 2003: 425-478). The elements of NPT used were the framework of the four stakeholder groups, although in our studies we sometimes only focused on one or two of them (but always including professional staff). The Technology Acceptance Model (TAM) comes from a software design perspective, and proposes that users 
are motivated to use an innovation by two factors - perceived usefulness and perceived ease of use. The StEAM approach focuses on developing a dialogue (with the researchers, but ideally also between the stakeholder groups) on the benefits of the innovation, alongside concerns and barriers that need to be overcome.

The four case studies aimed to elicit perceptions and attitudes to technological change through discussion with clinical staff delivering (or potentially delivering) services. This work has identified barriers, but also some enablers and best practice for ensuring successful adoption at scale. The evidence for the barriers and enablers can be grouped into the key themes, described in the next section. We have summarised in Table 1 the different health professionals involved in the four studies. Note that other categories of stakeholders were also involved, but are not discussed here.

Table 1. Categories of staff in the four different case studies, quoted below

\begin{tabular}{|l|l|}
\hline Study & Study participants (health professionals) \\
\hline $\begin{array}{l}\text { Remote swallowing assessment } \\
\text { (teleswallowing) }\end{array}$ & $\begin{array}{l}\text { Speech \& Language Therapist (SLT), Nursing Home } \\
\text { Nurse }\end{array}$ \\
\hline $\begin{array}{l}\text { Video-linked home dialysis support } \\
\text { (renal telemedicine) }\end{array}$ & Nurse \\
\hline $\begin{array}{l}\text { Video-linked fetal ultrasound shared } \\
\text { consultation (fetal telemedicine }\end{array}$ & Consultant, Sonographer \\
\hline $\begin{array}{l}\text { Survey of mental health } \\
\text { professionals }\end{array}$ & $\begin{array}{l}\text { Third Sector Mental Health Worker, Mental Health } \\
\text { Nurse, Consultant Psychiatrist, Mental Health } \\
\text { Professional }\end{array}$ \\
\hline
\end{tabular}

\section{Emerging themes for workforce development}

The findings from the four studies, later discussions, and published literature are grouped below as workforce barriers to, and enablers of, adoption of telemedicine practice. The themes we identified are used as sub-headings.

\section{Barriers to adoption of telemedicine in clinical practice}

\section{Concerns about being able to use technology}

Many respondents commented that they had initial misgivings on whether the technology required would work effectively, or whether they would have the skills to use it. This often reflected historical bad experiences with unfinished IT solutions being rolled out unsuccessfully, and indeed there were teething problems within two of the pilots. Front-line staff did not feel confident - and indeed did not have sufficient time - to solve IT problems in front of patients, which meant that they were often reluctant to commit to using new telemedicine technology in their practice. Suppliers, internal technical teams, and the clinical innovators themselves consistently underestimated the time needed for 'safe experimentation'.

A further problem was that, even when training or familiarisation time was planned in, health professionals were under so much time pressure that they were not able to dedicate time away from their core tasks. 
Technological problems can turn enthusiastic users into neutral users (Vuononvirta et al. 2009: 290-296), with equipment problems frequently being mentioned as a barrier to acceptance amongst staff (Brewster et al. 2014: 21-33, Taylor et al. 2015: 326-337).

There can be only one chance - if equipment does not inspire confidence, it will lead to distrust by staff. Those who were not confident in their ability would resist learning to become so (Vuononvirta et al. 2011: 190-194). Conversely, dedicated technical support was an important facilitator of implementation (Brewster et al. 2014: 21-33, Odeh et al. 2014: 1133-1137).

\section{Concerns about their changing job role}

In two of the studies, the teleswallowing and the fetal telemedicine projects, the model was for a health professional (a nurse and a sonographer, respectively) to undertake a physical examination under the guidance of a remote specialist (a SLT and a consultant, respectively). In the case of the teleswallowing project, there were comments from SLTs that they found this way of working to be challenging, although the nurses involved adapted very happily. Some SLTs initially had a view that this was not what they had been trained to do, and expressed some reluctance to engage with the patient through a third party.

In the fetal telemedicine case, the sonographers (the directed party) found being directed difficult, commenting that they had to suspend what they knew how to do instinctively and that they felt they were being made to look less capable as a result. The consultant, who did the directing, found it more straightforward to adapt to the role in this case.

This issue was also highlighted by Brewster et al. (2014: 21-33), who noted concerns with maintenance of professional identity and credibility, which could be undermined if staff were unconfident with equipment. Sharing responsibility for telehealth (telemedicine) with other professionals caused anxiety. Taylor et al. (2015: 326-337) noted concerns about the impact of telehealth on nursing roles and uncertainty about responsibility for patients due to the shared delivery of care. The introduction of tele-solutions necessitates new working relationships, at variance with accustomed divisions of labour. Tensions can occur when the tele-solution appears to impinge in/on another's domain (Segar et al. 2013: 606-613). A recurrent theme from those not delivering telehealth (telemedicine) was anxiety over how the tele-service might change or undermine professional roles, for example concerns amongst practice nurses over an "erosion of tasks and responsibilities". Telemedicine interventions can change work and communication flows, as well as altering (or increasing) workload, according to Moeckli et al. (2013: 890-901). Moeckli et al. and other authors have highlighted that some staff feel their professional roles are challenged by tele-applications (Buck 2009: 55-58, Dorsey and Topol 2016: 154-161, Joseph et al. 2011: 71-77, Moeckli et al. 2013: 890-901, Segar et al. 2013: 606613).

\section{Inability to see wider benefits}

In all the case studies, there were concurrent staff recruitment and retention issues, which, unfortunately, meant that the benefits to the patients in reducing inconvenience and expense, and to the service in increased productivity, had no direct benefit to the health professionals. The SLTs found any time savings resulting from telemedicine to be promptly used up dealing with other patients on waiting lists. Similarly the sonographers in the fetal telemedicine pilot were in fact required to do additional work through a shared consultation rather than a referral. Mental health professionals were more focused on patients already receiving care than by those on waiting lists for an initial assessment, so did not see the benefit of offering those people an initial consultation by video. Where staff do not understand or are unaware of the wider benefits, this can be a barrier (Buck 2009: 55-58, Odeh et al. 2014: 1133-1137, Taylor et al. 2015: 326-337, Wade et al. 2010: 190-201). Buck (2009: 55-58) argues that "the added value of a telemedicine application must be made crystal clear" and that many innovations have failed because benefits have not been made widely known. 
In just one of our studies, the renal nurses found their additional time could be used to catch up on other tasks, which they valued. The fetal sonographers also noted that there were benefits to hearing the consultant's advice and counselling to patients, which they would not otherwise have done.

\section{Other concerns}

There were various less clear, but negative comments related to loss of control or to other aspects of change. Although respondents tended to be less specific about their concerns, in all the studies it was clear that staff were operating in highly stressful work situations, and any change could be seen as problematic. More specific concerns are reported by Joseph et al., who report that staff can have redundancy fears, or worries over increased workload (Joseph et al. 2011: 71-77). A small number of respondents raised concerns about accountability, governance, and liability issues. This came out particularly in shared consultations.

Governance problems and procedures are also highlighted as an issue by French et al. (2013: 125), recommending that it is important to clarify where clinical responsibility lies at each stage of the patient pathway. Similarly, medico-legal concerns are highlighted in several other studies (Brewster et al. 2014: 21-33, Dorsey and Topol 2016: 154-161, Jayasinghe, Crowder, and Wills 2016: 3, Young, Chan, and Cram 2011: 279-288).

\section{Enablers of change}

In three of the four studies (renal telemedicine, remote swallowing assessment, fetal telemedicine), the services were eventually implemented following a pilot, and work on overcoming staff concerns. Staff were invited to reflect on what had influenced them in accepting the innovation. Similarly, respondents to the mental health survey were asked to consider the benefits, and what would encourage them to use telemedicine.

\section{Leadership from colleagues and senior executives}

The culture of innovation within healthcare is for management to be the 'gatekeeper', and require the 'clinical innovator' to prove their innovation and present a business case. This is facilitated by release of small and staged payments (either externally or internally funded), and sometimes by some form of executive sponsorship, often from IT or another department. Whilst management may think that this stance is one to promote neutrality, a lack of sponsorship of innovation can be perceived negatively.

Where management did intervene to show support and positive reinforcement of an innovation project, those projects proceeded more successfully (Bidmead et al. 2015: 155-168).

Zanaboni and Wootton (2012: 1) reflect that there is a need to understand professional incentivisation of health professionals as well as the financial benefits to the organisation (and possibly the patient, depending on health system).Taylor et al. (2015: 326-337) assert that engagement from commissioners and strategic managers is a facilitator of telehealth adoption.

\section{Peer motivation}

In all the pilot cases we studied, there was one person who acted as a 'champion' for the project, the clinical innovator. Within the wider team, there were individuals who were enthusiastic to try out the technology and individuals who were very negative and would not engage. As more of their peers got involved, more of the team became enthusiastic. It was significantly more motivating if a team member recommended the technology than if someone from another clinical service or a technical colleague did so.

Vuononvirta et al. (2009: 290-296) relate telehealth adoption to Rogers' framework (Rogers 1995), with critical users, or champions, being classified as 'early adopters' and the more hesitant staff as 'late majority'. There is a need to persuade and influence differently across the 
various categories in the framework. Many articles report the value of clinical champions (Brewster et al. 2014: 21-33, Joseph et al. 2011: 71-77, Peddle 2007: 595-614), but also highlighted are situations where their involvement is less successful (Brewster et al. 2014: 2133). Over-reliance on a single person can also make services vulnerable (Wade et al. 2010: 190201).

\section{Time for safe experimentation}

There have been many cases of new IT services being rolled out and imposed on health professionals. Technical staff sometimes underestimate the stress that is involved in trying out something new within a patient consultation, where time is already limited. This made many respondents wary. Experience has shown that much more time is required for staff to familiarise themselves with equipment and a new technique, before rolling it out at scale.

Mullen-Fortino et al. (Mullen-Fortino et al. 2012: 24-32) indicate that time should be spent in building personal relationships between staff who may need to work together on a telemedicine intervention. Armfield, Donovan, and Smith (Armfield, Donovan, and Smith 2010: 1-9) surveyed respondents taking part in a trial of telemedicine in a neonatal unit, who indicated that confidence, skills, and the ability to develop appropriate applications all improved with usage of the equipment.

\section{Patient benefits}

There is little doubt that telemedicine can be much more convenient for patients, reduce patient travel time and costs, and limit the need for clinical staff travel. This is expected to convert to better clinical outcomes, but due to the complexity of the interventions, the direct cause and effect can be hard to unravel. Nevertheless, significant anecdotal evidence exists and, in the case studies described, stories of patient benefits were found to motivate staff.

\section{A system-level approach to professional workforce development, education, and training}

The introduction of telemedicine at scale requires an organisational and system-level approach that recognises the specific challenges and issues (Dorsey and Topol 2016: 154-161). Such a change will be disruptive to work practices, professional roles, and to relationships with patients. However, although disruptive, the changes are dispersed and often incremental, making it hard for a direct cost benefit to be associated. Instead, there is a need for strong decision-making based on expectations, rather than on hard evidence.

Introduction of new technologies to date is normally technically or clinically led, service or patient-group specific, and often carried out in a piecemeal way. Both the non-innovating clinical professionals and managers see themselves in a kind of gatekeeper role, judging whether or not the technology should be adopted at the end of an agreed pilot period. A more successful model is to recognise that tools in use for domestic and leisure purposes (e.g. video conferencing tools) have a value clinically, but that the usage will depend on individual practice. All professions need to be empowered to modify their own practice using tools that have been generically approved by their organisation, so that, for example, a health visitor should be able to choose to use video or phone call instead of a specific patient visit, but to carry out other visits face-to-face where this is more appropriate. An approach to considering suitable tools in a field of practice may start with a review in that area (for example, stroke [French et al. 2013: 125, Sørensen et al. 2014: 1], primary care [Downes et al. 2015: 1], neonatal care [Bell et al. 2016: 149-154, Downes et al. 2015: 1]).

Our findings indicate that there is a need for professional development, skills training, and education at all levels: from entry level, through the different professional grades through to senior management. Greenhalgh, Swinglehurst, and Stones discuss clinician resistance to new 
types of technology under four categories: resistance to policy, resistance to material aspects of the technology itself, resistance to compromised professional practice, and to compromised professional relationships (Greenhalgh, Swinglehurst, and Stones 2014: 1-86).

There is clearly work to be done to explore how technological change is bound up with perceived erosion of professional identities. However, those professional identities are made and developed within an educational process. If this process enables reflection, personal development and growth of a professional identity - as it should do - the impact of change may be seen more positively.

We propose a system-level approach to developing and empowering the workforce, at all levels, to equip them with skills to select technologies and tools that can enhance their own clinical practice, to modify them, and to embed them in clinical services, at scale.

Table 2 summarises the skills and knowledge that could be provided to different professionals, either through profession-specific education and training, or as part of their continuing professional development (CPD).

Table 2. Indicative training needs across organisational roles

\begin{tabular}{|c|c|c|}
\hline $\begin{array}{l}\text { Professional role or } \\
\text { organisational level }\end{array}$ & Knowledge and skill needs & How it may be provided \\
\hline $\begin{array}{l}\text { Senior managers and } \\
\text { directors }\end{array}$ & $\begin{array}{l}\text { Strategic thinking; } \\
\text { Organisational strategy; } \\
\text { Partnership working; } \\
\text { Patient selection and workforce } \\
\text { planning; } \\
\text { Technology selection and } \\
\text { procurement; } \\
\text { Measures of success. }\end{array}$ & $\begin{array}{l}\text { Coaching and mentoring; } \\
\text { Structured planning } \\
\text { workshops; } \\
\text { Trusted information sources } \\
\text { to approved products. }\end{array}$ \\
\hline $\begin{array}{l}\text { Service managers, clinical } \\
\text { leads, advanced } \\
\text { practitioners, } \\
\text { commissioners }\end{array}$ & $\begin{array}{l}\text { Service re-design and } \\
\text { improvement; } \\
\text { Overview of suitable technology } \\
\text { tools; } \\
\text { Understanding of delivery } \\
\text { issues (security and privacy, } \\
\text { information governance, ethics); } \\
\text { Risk and project management } \\
\text { for innovation; } \\
\text { Supporting self-management } \\
\text { enabled by technology. }\end{array}$ & $\begin{array}{l}\text { CPD ; } \\
\text { Postgraduate qualifications } \\
\text { (e.g. MSc;) } \\
\text { Work-based training. }\end{array}$ \\
\hline Service delivery & $\begin{array}{l}\text { Delivering care using video; } \\
\text { Safe experimentation; } \\
\text { Case studies of best practice; } \\
\text { Hands on use of technology. }\end{array}$ & $\begin{array}{l}\text { Influence educational } \\
\text { bodies to incorporate in } \\
\text { core training; } \\
\text { Supplier training courses; } \\
\text { Work-based training; } \\
\text { CPD. }\end{array}$ \\
\hline $\begin{array}{l}\text { Competency based training } \\
\text { and updating }\end{array}$ & $\begin{array}{l}\text { IT skills; } \\
\text { Use of video technology. }\end{array}$ & $\begin{array}{l}\text { Supplier training courses; } \\
\text { Use of non-work skills and } \\
\text { technologies (e.g. } \\
\text { FaceTime and Skype) for } \\
\text { practice. }\end{array}$ \\
\hline
\end{tabular}




\section{Conclusion}

Telemedicine offers significant opportunities for improving healthcare and supporting patients more conveniently. Many pilots and studies have been undertaken, identifying benefits to patients in improving access, offering convenience and possible cost savings. Emerging evidence shows, however, that the impact on the clinical workforce is less clear cut, with both positive and negative changes to their practice. Further study of the evidence suggests that some of the barriers to adoption of telemedicine at scale are due to negative perceptions by professional staff. These can be overcome by a system-level approach to skills development and management.

\section{Acknowledgements}

This work was drawn from individually funded projects, but was not funded directly as such. We acknowledge the University of Cumbria for providing us with protected time to complete this meta-analysis and co-authors from the separate projects Dr Jae-Llane Ditchburn, Dr Tilly Reid, and Veronica Southern. This research received no specific grant from any funding agency in the public, commercial, or not-for-profit sectors. 


\section{References}

Armfield, N.R., Donovan, T., and Smith, A.C. (2010) 'Clinicians' perceptions of telemedicine for remote neonatal consultation'. Studies in Health Technology and Informatics, 161, 1-9

Bell, R.C., Yager, P.H., Clark, M.E., Roumiantsev, S., Venancio, H.L., Chipman, D.W., . . Noviski, N.N. (2016) 'Telemedicine versus face-to-face evaluations by respiratory therapists of mechanically ventilated neonates and children: A pilot study'. Respiratory Care, 61 (2), 149-154 https://doi.org/10.4187/respcare.04080

Bidmead, E. and Marshall, A. (Forthcoming) 'Staff user stakeholder perceptions in a fetal telemedicine case study'.

Bidmead, E., Reid, T., Marshall, A., and Southern, V. (2015) "'Teleswallowing": A case study of remote swallowing assessment'. Clinical Governance: An International Journal, 20 (3), 155-168 https://doi.org/10.1108/CGIJ-06-2015-0020

Brewster, L., Mountain, G., Wessels, B., Kelly, C., and Hawley, M. (2014) 'Factors affecting front line staff acceptance of telehealth technologies: A mixed-method systematic review'. Journal of Advanced Nursing, 70 (1), 21-33 https://doi.org/10.1111/jan.12196

Buck, S. (2009) 'Nine human factors contributing to the user acceptance of telemedicine applications: A cognitive-emotional approach'. Journal of Telemedicine and Telecare, 15 (2), 55-58 https://doi.org/10.1258/jtt.2008.008007

Davis, F.D. (1989) 'Perceived usefulness, perceived ease of use, and user acceptance of information technology'. MIS Quarterly, 13 (3), 319-340 https://doi.org/10.2307/249008

Ditchburn, J.-L. and Marshall, A. (2017) 'Renal telemedicine through video-as-a-service delivered to patients on home dialysis: A qualitative study on the renal care team members' experience'. Journal of Renal Care, 43 (3), 175-182 https://doi.org/10.1111/jorc.12207

Dorsey, E.R. and Topol, E.J. (2016) 'State of telehealth'. New England Journal of Medicine, 375 (2), 154-161 https://doi.org/10.1056/NEJMra1601705

Downes, M.J., Mervin, M.C., Byrnes, J.M., and Scuffham, P.A. (2015) 'Telemedicine for general practice: A systematic review protocol'. Systematic Reviews [online] 4 (1), 1 https://doi.org/10.1186/s13643-015-0115-2

Ekeland, A.G., Bowes, A., and Flottorp, S. (2010) 'Effectiveness of telemedicine: A systematic review of reviews'. International Journal of Medical Informatics, 79 (11), 736-771 https://doi.org/10.1016/.ijmedinf.2010.08.006

French, B., Day, E., Watkins, C., McLoughlin, A., Fitzgerald, J., Leathley, M., ... Lightbody, C. (2013) 'The challenges of implementing a telestroke network: A systematic review and case study'. BMC Medical Informatics and Decision Making [online] 13, 125 https://doi.org/10.1186/1472-6947-13-125

Greenhalgh, T., Swinglehurst, D., and Stones, R. (2014) 'Rethinking resistance to "big IT": A sociological study of why and when healthcare staff do not use nationally mandated information and communication technologies. Health Services and Delivery Research, 2 (39), 1-86 https://doi.org/10.3310/hsdr02390

Jayasinghe, D., Crowder, R.M., and Wills, G. (2016) 'Model for the adoption of telemedicine in Sri Lanka'. Sage Open [online] 6 (3) https://doi.org/10.1177/2158244016668565 
Joseph, V., West, R.M., Shickle, D., Keen, J., and Clamp, S. (2011) 'Key challenges in the development and implementation of telehealth projects'. Journal of Telemedicine and Telecare, 17 (2), 71-77 https://doi.org/10.1258/jtt.2010.100315

LeRouge, C., Garfield, M.J., and Collins, R.W. (2012) 'Telemedicine: Technology mediated service relationship, encounter, or something else?' International Journal of Medical Informatics, 81 (9), 622-636 https://doi.org/10.1016/j.ijmedinf.2012.04.001

Marshall, A. (2013) 'Designing telemedicine apps that health commissioners will adopt'. Proceedings of the 14th Conference of Open Innovations Association FRUCT, Finland November 2013 [online] IEEE 63-68. available from https://doi.org/10.1109/FRUCT.2013.6737946 [19 February 2018]

May, C.R. and Finch, T. (2009) 'Implementing, embedding, and integrating practices: An outline of Normalization Process Theory'. Sociology, 43, 535-554 https://doi.org/10.1177/0038038509103208

May, C.R., Mair, F., Finch, T., MacFarlane, A., Dowrick, C., Treweek, S., . . Montori, V.M. (2009) 'Development of a theory of implementation and integration: Normalization Process Theory'. Implementation Science [online] 4, 29 https://doi.org/10.1186/17485908-4-29

Moeckli, J., Cram, P., Cunningham, C., and Reisinger, H.S. (2013) 'Staff acceptance of a telemedicine intensive care unit program: A qualitative study'. Journal of Critical Care, 28 (6), 890-901 https://doi.org/10.1016/i.jcrc.2013.05.008

Mullen-Fortino, M., DiMartino, J., Entrikin, L., Mulliner, S., Hanson, C.W., and Kahn, J.M. (2012) 'Bedside nurses' perceptions of intensive care unit telemedicine'. American Journal of Critical Care, 21 (1), 24-32 https://doi.org/10.4037/ajcc2012801

NHS England (2014) Five Year Forward View [online] available from https://www.england.nhs.uk/wp-content/uploads/2014/10/5yfv-web.pdf [5 February 2018]

NHS Scotland (2015) e-Health Strategy 2014-2017 [online] available from http://www.gov.scot/Publications/2015/03/5705 [5 February 2018]

Odeh, B., Kayyali, R., Nabhani-Gebara, S.N., and Philip, N. (2014) 'Implementing a telehealth service: Nurses' perceptions and experiences'. British Journal of Nursing, 23 (21) 11331137 https://doi.org/10.12968/bjon.2014.23.21.1133

Peddle, K. (2007) 'Telehealth in context: Socio-technical barriers to telehealth use in Labrador, Canada'. Computer Supported Cooperative Work (CSCW), 16 (6), 595-614 https://doi.org/10.1007/s10606-006-9030-3

Rogers, E.M. (1995) Diffusion of Innovations. 4th edn. New York, NY: Free Press

Saliba, V., Legido-Quigley, H., Hallik, R., Aaviksoo, A., Car, J., and McKee, M. (2012) 'Telemedicine across borders: A systematic review of factors that hinder or support implementation'. International Journal of Medical Informatics, 81 (12), 793-809 https://doi.org/10.1016/j.ijmedinf.2012.08.003

Segar, J., Rogers, A., Salisbury, C., and Thomas, C. (2013) 'Roles and identities in transition: Boundaries of work and inter-professional relationships at the interface between 
telehealth and primary care'. Health \& Social Care in the Community, 21 (6), 606-613 https://doi.org/10.1111/hsc.12047

Smith, A.C. and Maeder, A.J. (2010) Global Telehealth: Selected Papers from Global Telehealth 2010 (GT2010): 15th International Conference of The International Society for Telemedicine and EHealth and 1st National Conference of the Australasian Telehealth Society [online] Amsterdam: IOS Press, eBook Collection (EBSCOhost) [6 December 2016]

Sørensen, T., Dyb, K., Rygh, E., Salvesen, R., and Thomassen, L. (2014) 'A qualitative description of telemedicine for acute stroke care in Norway: Technology is not the issue'. BMC Health Services Research [online] 14, 643 https://doi.org/10.1186/s12913-014$\underline{0643-9}$

Taylor, J., Coates, E., Brewster, L., Mountain, G., Wessels, B., and Hawley, M.S. (2015) 'Examining the use of telehealth in community nursing: Identifying the factors affecting frontline staff acceptance and telehealth adoption'. Journal of Advanced Nursing, 71 (2), 326-337 https://doi.org/10.1111/jan.12480

University of Cumbria for the Cumbria Rural Health Forum (2016) Digital Technology for Mental Health Survey of Mental Health Professionals in Cumbria, March 2016. [online] available from

http://www.ruralhealthlink.co.uk/assets/uploads/reports/Digital Technology for Mental Health Audit - Final Report.pdf [5 February 2018]

Venkatesh, V., Morris, M.G., Davis, G.B., and Davis, F.D. (2003) 'User acceptance of information technology: Toward a unified view'. MIS Quarterly, 27 (3), 425-478 https://doi.org/10.2307/30036540

Verhoeven, F., van Gemert-Pijnen, L., Dijkstra, K., Nijland, N., Seydel, E., and Steehouder, M. (2007) 'The contribution of teleconsultation and videoconferencing to diabetes care: A systematic literature review'. Journal of Medical Internet Research [online] 9 (5), e37, https://doi.org/10.2196/jmir.9.5.e37

Volpe, T., Boydell, K.M., and Pignatiello, A. (2013) 'Attracting child psychiatrists to a televideo consultation service: The TeleLink experience'. International Journal of Telemedicine and Applications [online] 2013, 146858 https://doi.org/10.1155/2013/146858

Vuononvirta, T., Timonen, M., Keinänen-Kiukaanniemi, S., Timonen, O., Ylitalo, K., Kanste, O., and Taanila, A. (2009) 'The attitudes of multiprofessional teams to telehealth adoption in northern Finland health centres'. Journal of Telemedicine and Telecare, 15 (6), 290-296 https://doi.org/10.1258/itt.2009.090108

Vuononvirta, T., Timonen, M., Keinänen-Kiukaanniemi, S., Timonen, O., Ylitalo, K., Kanste, O., and Taanila, A. (2011) 'The compatibility of telehealth with health-care delivery'. Journal of Telemedicine and Telecare, 17 (4), 190-194 https://doi.org/10.1258/jtt.2010.100502

Wade, V., Eliott, J., Karnon, J., and Elshaug, A.G. (2010) 'A qualitative study of sustainability and vulnerability in Australian telehealth services'. Studies in Health Technology and Informatics, 161, 190-201

Young, L.B., Chan, P.S., and Cram, P. (2011) 'Staff acceptance of tele-ICU coverage: A systematic review'. Chest Journal, 139 (2), 279-288 https://doi.org/10.1378/chest.10$\underline{1795}$ 
Zanaboni, P. and Wootton, R. (2012) 'Adoption of telemedicine: From pilot stage to routine delivery'. BMC Medical Informatics and Decision Making [online] 12, 1 https://doi.org/10.1186/1472-6947-12-1 